\title{
Effects of substituents on the rates of addition of 2-phenylpropionitrile carbanion to nitroarenes
}

\author{
Mieczysław Mąkosza,* Maciej Gola, and Daniel Sulikowski \\ Institute of Organic Chemistry, Polish Academy of Sciences, ul. Kasprzaka 44/52, \\ 01-224 Warszawa 42, POB 58, Poland \\ E-mail: icho-s@icho.edu.pl
}

\section{Dedicated to Professor Henk van der Plas on the occasion of his 80th Anniversary}

\begin{abstract}
The effects of substituents located ortho- and meta- to the nitro group in nitroarenes on the rates of addition of 2-phenylpropionitrile carbanion at the para-position were determined using oxidative nucleophilic substitution of hydrogen as the model process via competitive experiments. It was shown that the observed overall effects result from the superposition of primary and secondary electronic and steric effects.
\end{abstract}

Keywords: Carbanions, nitroarenes, oxidative nucleophilic substitution, competitive experiments

\section{Introduction}

Nucleophilic substitution of hydrogen in electron-deficient arenes is a well established, versatile tool in organic synthesis. ${ }^{1,4}$ The key step of this process is the addition of nucleophilic agents to these arenes to produce $\sigma^{\mathrm{H}}$ - adducts that are subsequently converted into the final products. The general character and value for synthesis of the nucleophilic substitution of hydrogen is due to the fact that the addition of nucleophiles in positions occupied with hydrogen leading to $\sigma^{\mathrm{H}}$ adducts proceeds faster than in those occupied by other substituents such as halogens. When the conversion of the $\sigma^{\mathrm{H}}$ - adducts into products proceeds at a high rate, the nucleophilic substitution of hydrogen becomes a general process that proceeds much faster than conventional substitution of halogens. There are two major ways for this conversion - the oxidation of the $\sigma^{\mathrm{H}}$ - adducts with external oxidants - oxidative nucleophilic substitution of hydrogen - "ONSH" 5 and the $\beta$ elimination of HX when the nucleophiles contain a leaving group $\mathrm{X}$ at the nucleophilic centre the vicarious nucleophilic substitution of hydrogen - "VNS". 6

Almost 30 years ago, Prof. van der Plas found that potassium permanganate forms a stable 
solution in liquid ammonia and that this solution can be used as an efficient system for amination of electron-deficient heteroarenes via oxidation of the $\sigma^{\mathrm{H}}$-adducts of ammonia. ${ }^{7}$ This oxidative variant of the Chichibabin reaction has found wide application in synthesis. ${ }^{8}$ Since liquid ammonia is an excellent solvent for the generation and reactions of carbanions, we have successfully used the system $\mathrm{KMnO}_{4} / \mathrm{NH}_{3}$ for ONSH in nitroarenes with carbanions of $\alpha$ phenylalkane nitriles ${ }^{9}$ and $\alpha$-phenylalkanoic acid derivatives. ${ }^{10}$

Recently we have shown that the VNS reaction can be used as an efficient tool for determination of the electrophilic activities of nitroarenes, particularly the effect of substituents on rates of addition of carbanions to electron-deficient aromatic rings. ${ }^{11,12}$ Although the effects of substituents on rates of nucleophilic substitution of halogens and other nucleofugal groups, the $\mathrm{S}_{\mathrm{N}} \mathrm{Ar}$ reaction, in substituted nitroarenes was thoroughly studied ${ }^{2,13}$ the resulting data do not reflect the true electrophilic activities of the arenes. The main reasons for this are that the $\mathrm{S}_{\mathrm{N}} \mathrm{Ar}$ reaction is a secondary process preceded by fast and reversible formation of the $\sigma^{\mathrm{H}}$ adducts, and that the observed rates depend on the nature of the leaving group. Contrary to that, the VNS reaction proceeds via addition of carbanions in positions occupied by hydrogen. As a result of this, we have used the VNS reaction and determined relative rates of the nucleophilic addition in the position occupied by hydrogen in nitroarenes for the model carbanions of chloromethyl phenyl sulfone in competitive experiments under conditions that assure fast elimination of $\mathrm{HCl}$ from the $\sigma^{\mathrm{H}}$ - adducts. ${ }^{11,12}$ Under such conditions the ratio of the products of the VNS reaction of competing nitroarenes reflects the ratio of the rate constants of the addition, and hence the electrophilic activity of arenes.

\section{Results and Discussion}

In this paper we present the results of similar studies of the effects of substituents on the rate of nucleophilic addition to nitroarenes of the model carbanion of 2-phenylpropionitrile 1 via $\mathrm{ONSH}$ reaction. In our earlier papers we reported that this is a fast reaction that proceeds selectively in the para position, in high yields. ${ }^{9}$ Due to these characteristics the ONSH reaction with carbanions of 2-phenylpropionitrile 1 can be used for determination of relative rates of nucleophilic addition to nitroarenes in positions para to the nitro group via competitive experiments. Since the ONSH with $\mathbf{1}^{-}$proceeds exclusively in the position para- to the nitro group, the effects of substituents that are located only in the ortho- and meta- positions to the nitro groups could be determined. In the competitive experiments, two nitroarenes $\mathbf{A}$ and $\mathbf{B}$ dissolved in liquid ammonia were competing for the carbanion of $\mathbf{1}$ used in sub- equimolar quantity. The mixture of the $\sigma^{\mathrm{H}}$ adducts produced, was subsequently oxidized with potassium permanganate, and the composition of the ONSH products analyzed by GLC. The ratio of the ONSH products reflects the relationship of the rate constants of the addition, provided oxidation of the $\sigma^{\mathrm{H}}$ adducts proceeds in high yields and faster than dissociation. The high rate of oxidation of the $\sigma^{\mathrm{H}}$ - adducts under these conditions has already been proved. ${ }^{9}$ In separate experiments we 
have shown that dissociation of the $\sigma^{\mathrm{H}}$ - adducts is a relatively slow process, much slower than the oxidation. Thus, when a solution of the $\sigma^{\mathrm{H}}$-adducts produced by addition of 1 to nitrobenzene in liquid ammonia at $-70^{\circ} \mathrm{C}$ was treated with an excess of $m$-chloronitrobenzene, and after a few minutes the mixture was oxidized with $\mathrm{KMnO}_{4}$ only the product of $\mathrm{ONSH}$ in nitrobenzene was formed, and thus the dissociation of the $\sigma^{\mathrm{H}}$ - adduct was not detected.

Initially the competitive experiments were carried out via addition of a solution of $\mathbf{1}^{-}$in liquid ammonia or THF to a solution of the competing nitro-arenes in liquid ammonia. However, due to very fast rate of the addition reaction, the results were irreproducible - perhaps the mixing at the low temperature was too slow, so local fluctuations of the concentration were generated. In order to avoid these difficulties the carbanion of $\mathbf{1}$ was generated in situ by treatment of a mixture of the competing nitro-arenes and the nitrile with a solution of $t$-BuOK in THF. Samples of the individual products of ONSH reaction necessary for calibration of GLC analyses were prepared as reported earlier. ${ }^{9}$

The competitive ONSH experiments are given in Scheme 1, results are given in Table 1.<smiles>O=[N+]([O-])c1ccccc1</smiles><smiles>CO[C@H](C)C(C)(C#N)C1C=CC(=[N+]([O-])[O-])C=C1</smiles>

PA

A<smiles>C=C=CC(C)=C(P)C#N</smiles><smiles>[Z]c1ccccc1[N+](=O)[O-]</smiles><smiles>[Z]C1C=CC(=[N+]([O-])[O-])C=CC1COC</smiles><smiles>CC(C#N)(c1ccccc1)c1ccc([N+](=O)[O-])cc1</smiles>

PB

\section{Scheme 1}

Competitive experiments of nitrobenzene with highly electrophilic nitroarenes gave mainly products of ONSH in these arenes, so GLC analysis of the mixtures of the products cannot give reliable results. To avoid these difficulties such nitroarenes: 2-F-, 3-CN-, 2-CN-nitrobenzenes, were allowed to compete with more active 2-Cl- nitrobenzene and subsequently between themselves, and the results recalculated for nitrobenzene which is used as the standard. 
Table 1. Results of the competition between nitrobenzene A and 2-Z- and 3-Z- substituted nitrobenzenes $\mathbf{B}$ for reaction with the carbanion of 2-phenylpropionitrile (as in Scheme 1), and for comparison - the relative activities of substituted nitroarenes in the VNS reaction ${ }^{11}$

\begin{tabular}{cccccc}
\hline $2-\mathrm{Z}$ & $\begin{array}{c}\text { Ratio of } \\
\mathrm{PB} / \mathrm{PA}\end{array}$ & $\mathrm{VNS}$ & $3-\mathrm{Z}$ & $\begin{array}{c}\text { Ratio of } \\
\text { PB/PA }\end{array}$ & $\mathrm{VNS}$ \\
\hline $\mathrm{MeO}$ & 0.030 & 0 & $\mathrm{MeO}$ & 0.44 & 1.1 \\
$\mathrm{I}$ & 0.54 & 0 & $3-\mathrm{I}$ & 0.64 & 31 \\
$\mathrm{H}$ & 1.0 & 1.0 & $\mathrm{H}$ & 1.0 & 1.0 \\
$\mathrm{Br}$ & 12 & 4.8 & $\mathrm{Br}$ & 1.9 & 170 \\
$\mathrm{Cl}$ & 16 & 6.3 & $\mathrm{Cl}$ & 14 & 260 \\
$\mathrm{COO}-i \mathrm{Pr}$ & 26 & 9.3 & $\mathrm{~F}$ & 21 & 17 \\
$\mathrm{CF}_{3}$ & 46 & 67 & $\mathrm{CN}$ & $1100(20)^{\mathrm{c}}$ & 5500 \\
$\mathrm{~F}$ & $110(7.0)^{\mathrm{a}}$ & 25 & $\mathrm{CF}_{3}$ & - & \\
$\mathrm{CN}$ & $8600(3.9)^{\mathrm{b}}$ & 1100 & $\mathrm{COOMe}^{2}$ & - & \\
\hline
\end{tabular}

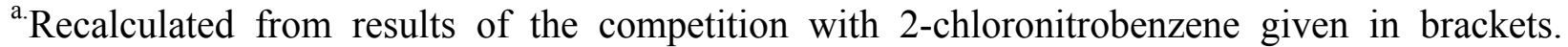
${ }^{b}$ Recalculated from the results of the competition with 3-cyanonitrobenzene given in brackets. ${ }^{\mathrm{c}}$ Recalculated from the results of the competition with 2-fluoronitrobenzene given in the brackets.

As was discussed in detail in our preceding papers, ${ }^{11,12}$ the rate of the nucleophilic addition to substituted nitroarenes can be affected by the substituents in a few ways: primary electronic: inductive and resonance effects on the reaction site, primary steric effect on the reaction site, and also secondary electronic and steric effects on the nitro- group that change its overall electronwithdrawing action activating nitro- aromatic rings. The observed relative rate constants of the addition of $\mathbf{1}^{-}$to nitroarenes are a superposition of these effects. Substituents $Z$ in $2-Z$ nitroarenes being in a meta-position to the reaction site, exert primary electronic inductive effect on the addition site, and secondary electronic and steric effects on the nitro group. For example, in the series of 2-halo-nitro-arenes, $\mathrm{F}>\mathrm{Cl}>\mathrm{Br}>\mathrm{H}>\mathrm{I}$, it is evident that the secondary steric effect that hinders co-planarity of the nitro group with the ring which is necessary for the addition, dominates over the secondary electron-donating effect of $\mathrm{F}$ in 2-F nitrobenzene. Thus, the overall effect is as show in the above sequence. The importance of the secondary steric effect can be seen in the case of $2-\mathrm{CF}_{3}-$ nitrobenzene. Although the $\mathrm{CF}_{3}$ group exerts a very strong electronwithdrawing inductive effect, (much stronger than F) and, unlike $\mathrm{F}$, has no electron- donating conjugative effect, 2- $\mathrm{CF}_{3}$ - nitrobenzene is less active than 2-F- nitrobenzene. On the other hand, in 3-Z- nitrobenzenes, the substituents $\mathrm{Z}$ act via primary electronic and steric effects on the addition site. Here one can observe the strong influence of primary steric effects. The presence of bulky and moderately electron-withdrawing halogens, I and $\mathrm{Br}$, respectively moderately decelerate, and slightly accelerate, the addition. Of particularly interest is $3-\mathrm{CF}_{3}$ nitrobenzene. This highly electron-deficient nitroarene adds $\mathbf{1}^{-}$to form $\sigma^{\mathrm{H}}$-adducts, but due to steric hindrances 
these $\sigma^{\mathrm{H}}$ adducts are not oxidized with $\mathrm{KMnO}_{4}$. The formation of $\sigma^{\mathrm{H}}$ - adducts of $\mathbf{1}^{-}$to $3-\mathrm{CF}_{3}-$ nitrobenzene was proved in an experiment in which $\mathbf{1}^{-}$was mixed with an equimolar amount of the nitro-arene and the mixture was treated with an excess of methyl iodide. Quenching of the mixture with $\mathrm{NH}_{4} \mathrm{Cl}$ leads to full recovery of 2-phenylpropionitrile, whereas in a similar experiment without 3- $\mathrm{CF}_{3}$-nitrobenzene, 2-methyl-2-phenylpropionitrile the product of methylation of the carbanion, was obtained. This indicated that the carbanion of $\mathbf{1}$ is bonded reversibly to $3-\mathrm{CF}_{3}$ nitrobenzene and the nitrile released upon protonation. The strongly electronwithdrawing $\mathrm{CN}$ group, that does not create steric hindrance, exerts the strongest activating effects in both the 2- and 3-positions. It is interesting to compare the effects of substituents on the relative rates of the addition of $\mathbf{1}^{-}$in the para-position of nitroarenes with those of the carbanion of chloromethyl phenyl sulfone (CPS) determined via VNS reaction. ${ }^{11}$ Although, in general, the trend is the same, there are substantial differences mostly due to the much stronger influence of steric effects on the addition and also the oxidation steps in the ONSH with 1. For instance, the overall activity of 3-chloronitrobenzene in the reaction with the secondary carbanion of CPS is about 40 times higher than the 2 -isomer, whereas in the reaction with $\mathbf{1}^{-}, 2-$ chloronitrobenzene is more active than the 3-isomer. A similar situation is the case with 2- and 3- bromonitrobenzenes. Obviously primary steric effects are dominating.

The ONSH competitive experiments gave a good opportunity to compare directly the rates of nucleophilic addition of $\mathbf{1}^{-}$to nitroarenes in positions para- to the nitro group and occupied by hydrogen and halogen. The latter addition is the first step of the $\mathrm{S}_{\mathrm{N}} \mathrm{Ar}$ reaction. Although direct competition of nitrobenzene with $p$-fluoro- and $p$-chloro- nitrobenzenes is not feasible, because the products of the ONSH reaction in nitrobenzene and $\mathrm{S}_{\mathrm{N}} \mathrm{Ar}$ in $p$-halonitrobenzenes are identical, such competition can be made between 4-halo-nitrobenzenes and nitrobenzenes containing substituents in positions 2- or 3- (Scheme 2).

The data in Scheme 2 do not indicate strong preference for the addition of $\mathbf{1}^{-}$in positions occupied by hydrogen. One should, however, take into account the high overall electrophilic activities of para- halonitrobenzenes that play an important role in the intermolecular competition, whereas in intramolecular competition the addition in positions occupied by hydrogen is much preferred. 


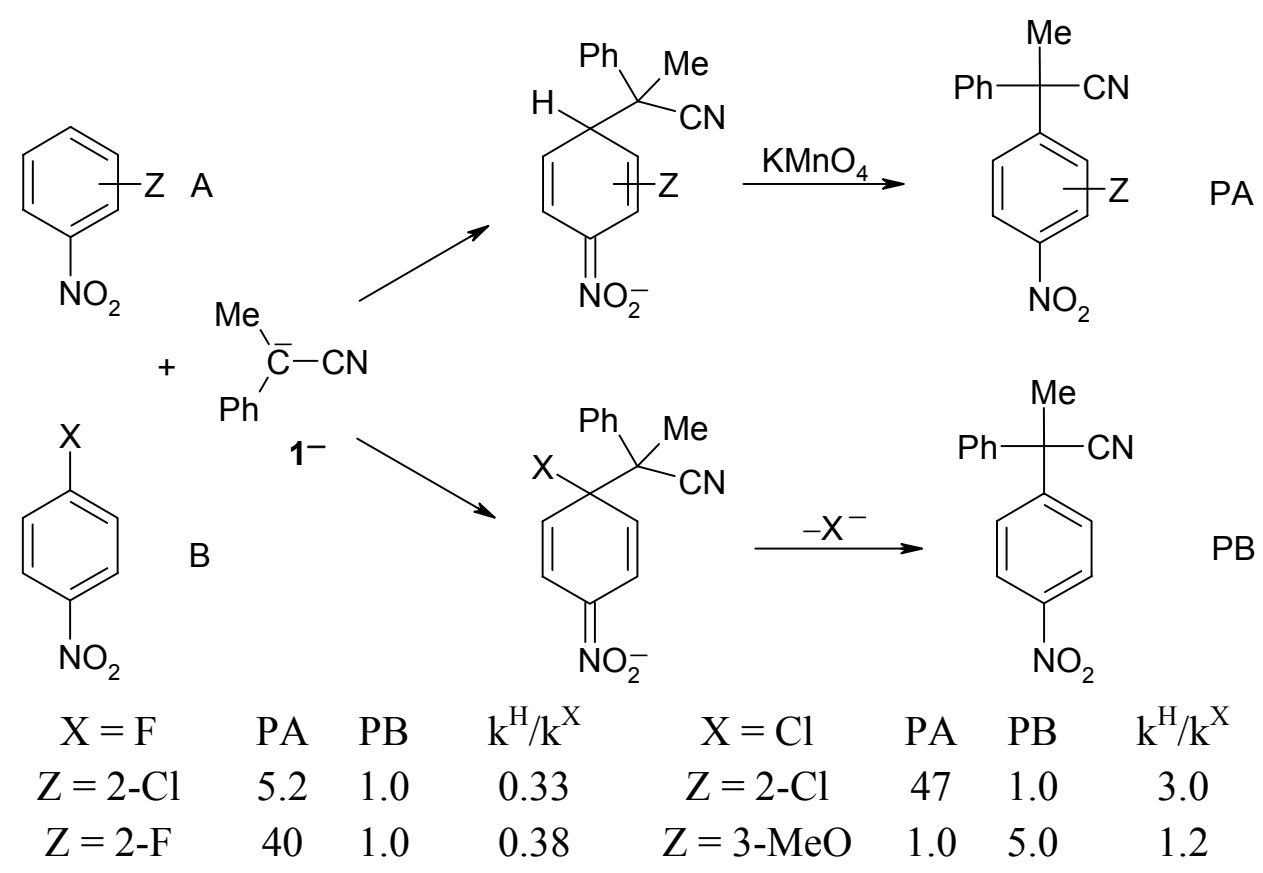

Scheme 2. $\mathrm{k}^{\mathrm{H}} / \mathrm{k}^{\mathrm{X}}$ ratio of the rates of addition of 1 in the para- position of nitrobenzene and the para- position of 4-X-nitrobenzenes.

\section{Conclusions}

It has been shown that the rate of addition of the tertiary carbanions of $\mathbf{1}$ in the para-positions of nitro-arenes is affected by electronic and steric effects of substituents. Particularly important are primary steric hindrances by substituents located in positions meta- to the nitro group. Due to the strong influence of the steric effects, ONSH in nitro-arenes with the tertiary carbanion of 2phenylpropionitrile cannot be a good model to study the electrophilicity of nitroarenes. On the other hand, the results disclose the complicated picture of the process and should be of substantial value for designing experiments on oxidative nucleophilic substitution with other carbanions.

\section{Experimental Section}

General Procedures. ${ }^{1} \mathrm{H}-,{ }^{13} \mathrm{C}$-, and ${ }^{19} \mathrm{~F}$ - NMR spectra were recorded with Varian Mercury 200 $\mathrm{MHz}$ or $400 \mathrm{MHz}$ instrument in $\mathrm{CDCl}_{3}$. Chemical shifts are expressed in ppm referred to TMS, with coupling constants in Hertz. Mass spectra were recorded with an AMD 604 Inectra GmbH (EI ionization) spectrometer. Merck silica gel 60 (230-400 mesh) was used for column chromatography. Merck aluminum foil Kieselgel 60/F254 was used for TLC. All solvents all were distilled prior to use. THF was distilled over potassium benzophenone ketyl. All reactions 
were carried out under argon atmosphere. Most of the reagents were commercially available. Isopropyl 4-nitrobenzoate- and isopropyl 2-nitrobenzoate were obtained according to known procedure from the appropriate acids. ${ }^{14}$ 1-nitro-2-(trifluoromethyl)benzene was obtained according to a known procedure. ${ }^{15}$ Most of the ONSH products were reported previously, ${ }^{9}$ and their spectroscopic data were identical with those reported. Calculation of the results of the competitive experiments were carried out as described earlier. ${ }^{11}$

\section{Preparative ONSH reaction in nitro-arenes. General procedure}

To a solution of 2-phenylpropionitrile $(1.0 \mathrm{mmol})$ and the nitro-arene $(1.0 \mathrm{mmol})$ in liquid $\mathrm{NH}_{3}$ $(20 \mathrm{~mL})$ cooled to $-70^{\circ} \mathrm{C}$ a $1 M$ solution of $t$-BuOK in THF $(1.1 \mathrm{~mL}, 1.1 \mathrm{mmol})$ was added dropwise. After $2 \mathrm{~min}$, powdered $\mathrm{KMnO}_{4}(0.24 \mathrm{~g}, 1.5 \mathrm{mmol})$ was added and after 2 min the reaction mixture treated with powdered $\mathrm{NH}_{4} \mathrm{Cl}(0.5 \mathrm{~g})$ and then ammonia evaporated. The residue was treated with water, extracted with $\mathrm{CH}_{2} \mathrm{Cl}_{2}(50 \mathrm{~mL})$ and passed through a small pad of Celite. Organic phase was dried with $\mathrm{MgSO}_{4}$ and evaporated. Products were isolated and purified by column chromatography (ethyl acetate/hexane).

\section{Competitive reactions. General procedure}

To a solution of competing nitroarenes A and B (2-6 mmol), biphenyl (internal standard) and 2phenylpropionitrile $(1 \mathrm{mmol})$ in $\mathrm{NH}_{3}(20 \mathrm{~mL})$ cooled to $-70^{\circ} \mathrm{C}$ a $1 \mathrm{M}$ solution of $t$-BuOK in THF $(1.1 \mathrm{~mL}, 1.1 \mathrm{mmol})$ was added dropwise. After $2 \mathrm{~min}$ powdered $\mathrm{KMnO}_{4}(0.24 \mathrm{~g}, 1.5 \mathrm{mmol})$ was added and after another 2 min the reaction mixture was treated with powdered $\mathrm{NH}_{4} \mathrm{Cl}(0.5 \mathrm{~g})$ and ammonia evaporated. The residue was treated with water, extracted with $\mathrm{CH}_{2} \mathrm{Cl}_{2}(50 \mathrm{~mL})$ and passed through a small pad of Celite. Extracts were dried with $\mathrm{MgSO}_{4}$ and analyzed by GLC using internal standard and calibration procedure. The reaction was repeated 3 times for each pair of nitroarenes and results were averaged. Calculation of the relative rates were carried out as reported earlier. $^{11,12}$

2-(4-Nitro-3-trifluoromethylphenyl)-2-phenyl-propionitrile. ${ }^{1} \mathrm{H}$ - NMR (400 MHz): $\delta 7.90(\mathrm{~d}$, $1 \mathrm{H}, J=8.6), 7.81(\mathrm{~d}, 1 \mathrm{H}, J=1.8), 7.75(\mathrm{dd}, 1 \mathrm{H}, J=8.4,2.2), 7.45-7.26(\mathrm{~m}, 4 \mathrm{H}), 2.16(\mathrm{~s}, 3 \mathrm{H})$; ${ }^{13} \mathrm{C}$ NMR (100 MHz): $\delta$ 147.4, 146.9, 138.7, 131.4, 129.5, 129.0, 126.5, $126.1(\mathrm{k}, J=5.17)$, 125.8, $124.4(\mathrm{k}, J=34.5), 121.6(\mathrm{k}, J=270), 121.7,46.1,27.8 ;{ }^{19} \mathrm{~F}$ NMR $(376 \mathrm{MHz}):-60.5(\mathrm{~s})$; MS-EI m/z (\%) 320 (M+, 28), 305 (100), 259 (18), 190 (33), 178 (12), 130 (8), 103 (10); Anal. Calcd. For $\mathrm{C}_{16} \mathrm{H}_{11} \mathrm{~F}_{3} \mathrm{~N}_{2} \mathrm{O}_{2}$ : C, 60.00; H, 3.46; N, 8.75; F, 17.00; found C, 60.22; H, 3.74; N, 8.70; F, 17.37 .

2-(4-Nitro-3-isopropoxycarbonylphenyl)-2-phenylpropionitrile. ${ }^{1} \mathrm{H}$ NMR $(200 \mathrm{MHz}): \delta 7.88$ $(\mathrm{d}, 1 \mathrm{H}, J=8.6), 7.74$ (d, $1 \mathrm{H}, J=2.2), 7.59$ (dd, $1 \mathrm{H}, J=8.6,0.6), 7.48-7.26(\mathrm{~m}, 4 \mathrm{H}), 5.25(\mathrm{~h}, 1 \mathrm{H}$, $J=6.4) 2.14(\mathrm{~s}, 3 \mathrm{H}), 1.34(\mathrm{~d}, 6 \mathrm{H}, J=6.4) ;{ }^{13} \mathrm{C} \mathrm{NMR}(50 \mathrm{MHz}): \delta 164.3,147.5,146.8,139.1$, $129.9,129.4,128.9,128.7,127.8,126.5,124.5,121.9,71.0,46.1,27.8,21.3 ;$ MS-EI m/z (\%) 338 $\left(\mathrm{M}^{+}, 13\right), 296$ (12), 279 (90), 263 (4), 252 (44), 237 (100), 190 (70) 179 (12) 164 (10), 150 (35), 103 (10); Anal. Calcd. For $\mathrm{C}_{19} \mathrm{H}_{18} \mathrm{~N}_{2} \mathrm{O}_{4}$ : C, 67.44; H, 5.31; N, 8.28; found C, 67.01; H, 5.41; N, 8.30 . 


\section{References}

1. Chupakhin, O. N.; Charushin, V. N.; van der Plas, H. C. Nucleophilic Aromatic Substitution of Hydrogen; Academic Press: San Diego, 1994.

2. Terrier, F. Nucleophilic Aromatic Displacement: The Influence of the Nitro Group; VCH: New York, 1991.

3. Mąkosza, M. Russ. Chem. Bull. 1996, 45, 491.

4. Mąkosza, M.; Wojciechowski, K. Chem. Rev. 2004, 104, 2631.

5. (a) Mąkosza, M.; Staliński, K. Pol. J. Chem. 1999, 73, 151. (b) Mąkosza, M.; Paszewski, M. Pol. J. Chem. 2005, 79, 163.

6. (a) Mąkosza, M.; Winiarski, J. Acc. Chem. Res. 1987, 20, 282. (b) Mąkosza, M.; Kwast, A. J. Phys. Org. Chem. 1998, 11, 341.

7. Counotte-Potman, A.; van der Plas, H. C. J. Heterocycl. Chem. 1981, 18, 123.

8. (a) Van der Plas, H. C.; Woźniak, M. Croat. Chim. Acta 1986, 59, 33. (b) Woźniak, M.; van der Plas, H. C. Acta Chem. Scand. 1993, 47, 95.

9. (a) Mąkosza, M.; Staliński, K. Chem. Eur. J. 1997, 3, 2025. (b) Mąkosza, M.; Staliński, K. Synthesis, 1998, 1633.

10. (a) Mąkosza, M; Surowiec, M.; Paszewski, M. ARKIVOC 2004, (ii), 172. (b) Mąkosza, M.; Kamieńska-Trela, K.; Paszewski, M.; Bechcicka, M. Tetrahedron, 2005, 61, 11952. (c) Florio, S., Mąkosza, M., Lorusso, P., Troisi, L. ARKIVOC, 2006, (vi), 59.

11. (a) Mąkosza, M.; Błażej, S.; Chem. Eur. J. 2008, 14, 11113. (b) Błażej, S.; Wileńska, B.; Voynova, N.S.; Mąkosza, M. Pol. J. Chem. 2008, 82, 2017.

12. Seelinger, F.; Błażej, S.; Bernhardt, S.; Makosza, M.; Mayr, H. Chem. Eur. J. 2008, 14, 6108.

13. Miller, J., Aromatic Nucleophilic Substitution; Elsevier: Amsterdam, 1968.

14. Vogel, A. I.; Furniss B. S.; Hannaford A. J.; Smith P. W. G.; Tatchell, A. R. Vogel's Textbook of Practical Organic Chemistry, 5th Edn.; Wiley: New York, 1989.

15. Clark, J. H.; Dennes, J. E.; McClinton, M. A.; Wynd, A. J., J. Fluor. Chem. 1990, 50, 411. 